Sensitivity of Primary Knock-on Atom Spectra and Displacement per Atom Cross-Sections to Different Secondary Neutron Energy and Angular Distributions and "In-Group" Weighting Schemes
T. A. Gabriel
B. L. Bishop

OAK RIDGE NATIONAL LABORATORY OPERATED BY UNION CARBIDE CORPORATION · FOR THE DEPARTMENT OF ENERGY 


\section{DISCLAIMER}

This report was prepared as an account of work sponsored by an agency of the United States Government. Neither the United States Government nor any agency Thereof, nor any of their employees, makes any warranty, express or implied, or assumes any legal liability or responsibility for the accuracy, completeness, or usefulness of any information, apparatus, product, or process disclosed, or represents that its use would not infringe privately owned rights. Reference herein to any specific commercial product, process, or service by trade name, trademark, manufacturer, or otherwise does not necessarily constitute or imply its endorsement, recommendation, or favoring by the United States Government or any agency thereof. The views and opinions of authors expressed herein do not necessarily state or reflect those of the United States Government or any agency thereof. 


\section{DISCLAIMER}

Portions of this document may be illegible in electronic image products. Images are produced from the best available original document. 
Printed in the United States of America. Available from National Technical Information Service

U.S. Department of Commerce

5285 Port Royal Road, Springfield, Virginia 22161

Price: Printed Copy $\$ 4.50$; Microfiche $\$ 3.00$

This report was prepared as an account of work sponsored by an agency of the United States Government. Neither the United States Government nor any agency thereof, nor any of their employees, contractors, subcontractors, or their employees, makes any warranty, express or implied, nor assumes any legal liability or responsibility for any third party's use or the results of such use of any information, apparatus, product or process disclosed in this report, nor represents that its use by such third party would not infringe privately owned rights. 
Contract No. W-7405-eng-26

Neutron Physics Division

\title{
SENSITIVITY OF PRIMARY KNOCK-ON ATOM SPECTRA AND \\ DISPLACEMENT PER ATOM CROSS SECTIONS TO \\ DIFFERENT SECONDARY NEUTRON ENERGY \\ AND ANGULAR DISTRIBUTIONS AND \\ "IN-GROUP" WEIGHTING SCHEMES*
}

T. A. Gabriel

B. L. Bishopt

Date Published - January 1978

\footnotetext{
¿ Submitted for journal publication.

${ }^{\dagger}$ Computer Sciences Division.
}

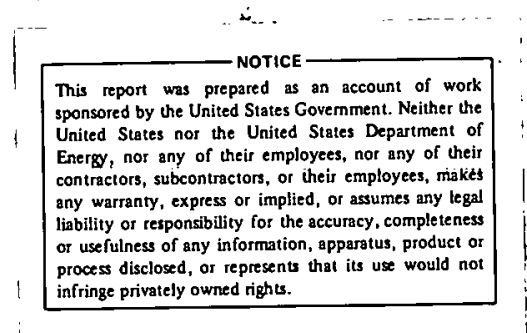

NOTICE This document contains information of a preliminary nature. It is subject to revision or correction and therefore does not represent a final report.

\author{
OAK RIDGE NATIONAL LABORATORY \\ Oak Ridge, Tennessee 37830 \\ operated by \\ UNION CARBIDE CORPORATION \\ for the \\ DEPARTMENT OF ENERGY
}


THIS PAGE

\section{WAS INTENTIONALLY LEFT BLANK}




\section{Abstract}

The sensitivity of primary knock-on atom (PKA) spectra and displacement per atom (DPA) cross sections to different secondary neutron energy and angular distributions and "in-group" weighting schemes is investigated. It is shown that the sensitivity of the PKA spectra and DPA cross sections for the $\left(n, n^{\prime}\right.$ unresolved) and $(n, 2 n)$ reactions in Fe to different angular distributions and the same secondary neutron spectrum is reasonably large ( 15\%) whereas the sensitivity of these quantities to grossly different secondary neutron spectra and the same angular distribution is unexpectedly small. It will also be shown that for $A 1$, the sensitivity of damage energy cross sections to different "in-group" weighting schemes is, for the most part, small. 


\section{INTRODUCTION}

Displacements per atom (DPA) and gas production cross sections are used to determine the effective damage levels that can be expected in structural metals when they are exposed to radiation environments. For neutron radiation environments, ENDFB/IV provides directly, in most cases, reasonable data for the gas production cross sections. However, DPA cross sections are obtained from primary knock-on atom (P'KA) spectra that must be deduced from ENDFB/IV data. For elastic and inelastic resolved neutron reactions, ENDFB/IV, in most cases, provides the necessary data by which PKA spectra can be obtained with essentially no approximations or assumptions. However, in general, for the remaining reactions, $\left(n, n^{\prime}\right.$ unresolved), $(n, p),(n, 2 n)$, etc., there are not sufficient data given so that totally definitive PKA spectra can be obtained without resorting to various assumptions and approximations. For example, one of the most common assumptions is that the angular distribution of the secondary neutrons is isotropic in the center-of-mass (C-M) system and that the secondary neutron energy distribution can be obtained from ENDFB/IV or from some sort of evaporation-type spectrum.

Presented in this paper is a set of calculations in. which the sensitivity of PKA spectra and DPA cross sections for the ( $n, n^{\prime}$ unresolved) and $(n, 2 n)$ reactions in $\mathrm{Fe}$ to different secondary neutron energy and angular distributions is investigated. It will be shown that the sensitivity of the PKA spectrum and DPA cross sections to different angular distributions and the same secondary neutron spectrum is reasonably large ( $\sim 15 \%$ ) whereas for grossly different secondary neutron spectra and the same angular distribution, the sensitivity is unexpectedly small. 
Also presented is the sensitivity of the damage energy cross sections to different "in-group" weighting, for example, constant, 1/E, $1 / E \sigma_{T}$. It is shown that for $A l$, the sensitivity is extremely small for all weightings except $1 / E \sigma_{T}$ and even this weighting produces only slightly different integral results:

The methods of calculation are presented in Sec. II and the results are presented and discussed in Sec. III.

\section{METHODS OF CALCULATION}

The neutron and PKA-energy group structures used in the calculations are given in Tables I and II. The neutron group structure up to $14.91 \mathrm{MeV}$ is the same as the GAM-II group structure. ${ }^{1}$ The PKA group structure used is based on equal lethargy intervals from $20 \mathrm{eV}$ to $10 \mathrm{MeV}$.

For elastic, inelastic, $(n, 2 n),(n, 3 n),(n, n p)$, etc. reactions involving the emission of mass 1 particles and excluding absorption reactions, a modified version of the XLACS module from the AMPX code system ${ }^{1}$ was used to calculate the PKA spectra. For elastic and inelastic resolved reactions, where angular distributions are usually available, the PKA spectra in the form of a neutron group $\left(g_{n}\right)$ to a PKA group $\left(g_{R}\right)$ transfer matrix were obtained from the following expression:

$$
\sigma\left(g_{n} \rightarrow g_{R}\right)=\frac{\left.\frac{1}{4 \pi} \sum_{m=1}^{M} w_{m} \int_{E_{10 W}}^{E_{h i g h}\left(\mu_{i l l}, g_{R}\right)} d E g_{R}\right)}{\int_{E \varepsilon g_{n}} d E \phi(E)}
$$


Table I

Neutron Group Structure (eV)

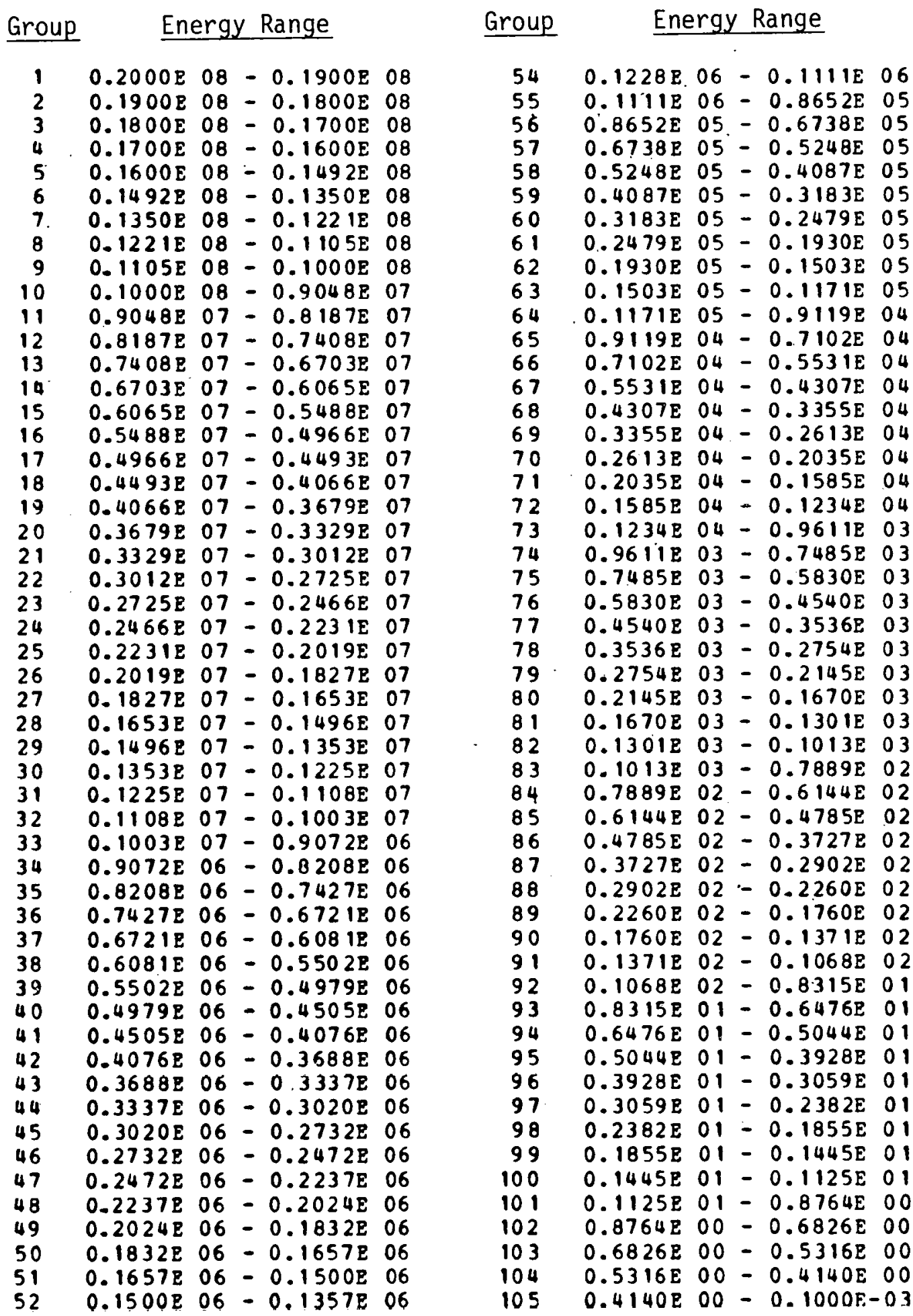


Table II

Primary Knock-On Atom Energy Group Structure (eV)

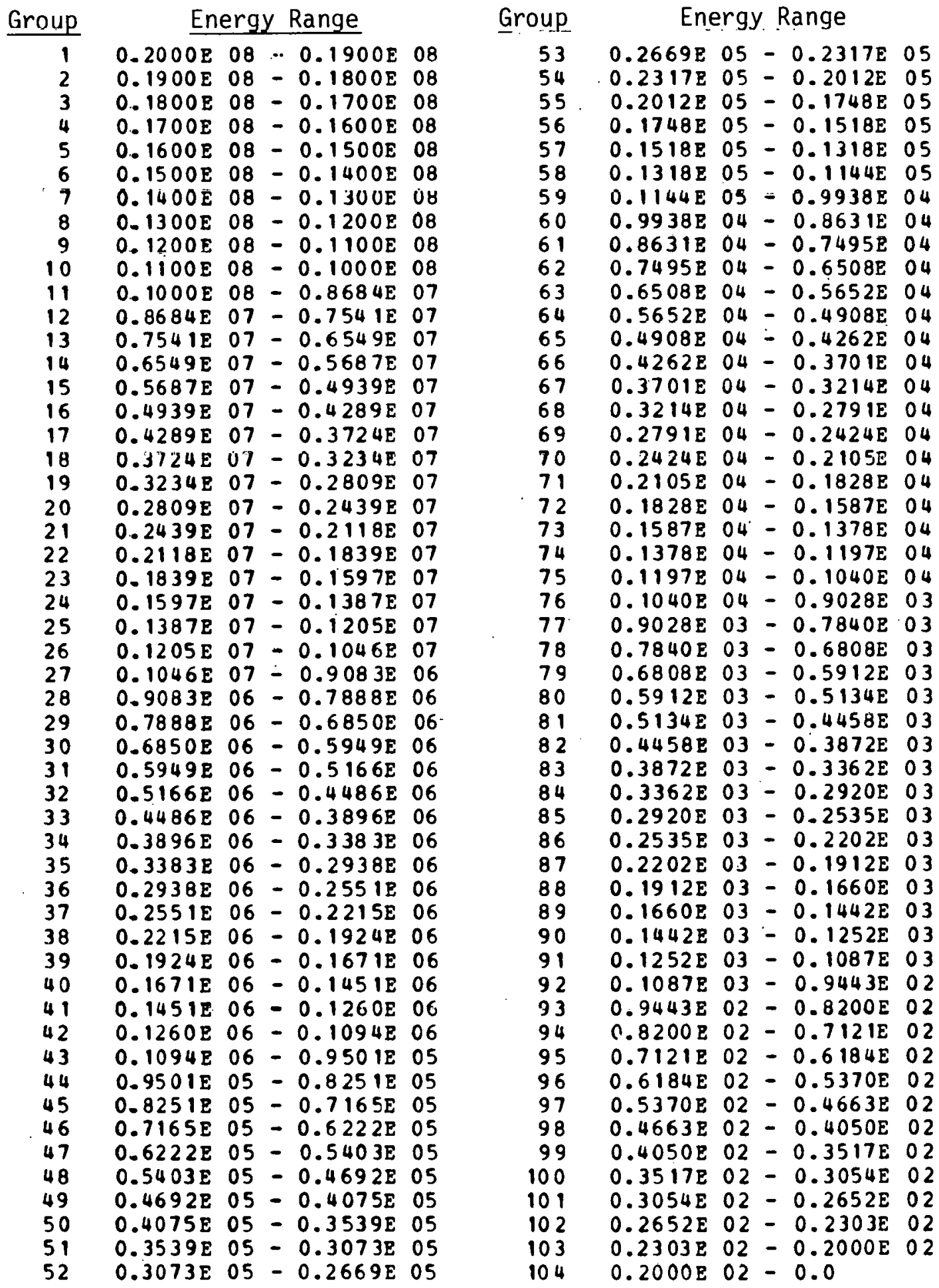


where

$$
\begin{aligned}
\sigma\left(E, \mu_{m}\right)= & \text { the neutron energy and angular dependence } \\
& \left(\mu_{m}=\cos \theta_{m}\right) \text { of the cross-section data obtained } \\
& \text { from ENDFB/IV, } \\
\phi(E)= & \text { the flux weighting factor taken to be one of the } \\
& \text { following: } 1 / E-M a x w e l l i a n \text { (standard), constant- } \\
& \text { Maxwellian (1), fission-l/E-Maxwellian (2), } \\
& 1 / E \sigma_{T}-\text { Maxweilian (3), } \\
w_{m}= & \text { the angular quadrature weights, and } \\
\sigma\left(g_{n} \rightarrow g_{R}\right)= & \text { the probability (or cross section) for a neutron in } \\
& \text { neutron group } g_{n} \text { to produce a PKA in group } g_{R} .
\end{aligned}
$$

This expression contains no complicated physics except for the determination of the limits on the $\mathrm{dE}$ integral, and these, of course, are determined through momentum and energy conservation. The calculations were carried out in the following way: for an angle $\mu_{m}$, the PKA energy range of $T_{\text {high }}$ and $T_{\text {low }}$ was determined from the expressions

$$
\begin{gathered}
T_{h}=n_{1} n_{2} E_{i j}+\left(n_{1} / n_{2}\right) E_{m, j}-2 n_{1}\left(E_{j} E_{m, j}\right)^{\frac{1}{2}} \mu_{m} \\
T_{1}=n_{1} n_{2} E_{j+1}+\left(n_{1} / n_{2}\right) E_{m, j+1}-2 n_{1}\left(E_{j+1} E_{m, j+1}\right)^{\frac{3}{2}} \mu_{m}
\end{gathered}
$$

where

$$
\begin{aligned}
& n_{1}=1.009 /(1.009+A), \\
& n_{2}=A /(1.009+A), \\
& A=\text { atomic number of the target, } \\
& E_{j}=\text { upper neutron energy for neutron group } j,
\end{aligned}
$$




$$
\begin{aligned}
E_{j+1} & =\text { lower neutron energy for neutron group } j, \\
E_{m, j} & =n_{2}\left(n_{2} E_{j}+Q_{j}\right)=\text { recoil neutron energy in the C-M system, } \\
Q_{i}= & \text { excitation energy for the } i \text { th level (for elastic } \\
& \text { scattering, } Q=0) .
\end{aligned}
$$

If $T_{h}$ and $T_{1}$ fall within one PKA group, the averaged neutron cross section is assigned to that group, and the calculation proceeds to the next angle. However, as is usually the case, $T_{h}$ and $T_{1}$ will span several PKA groups. Therefore, starting with the energy of the first PKA group $T_{k}$ above the PKA energy $T_{j}$, the neutron energy. $E_{k}$ (between $E_{j}$ and $E_{j+1}$ ) is determined from Eq. (1b). The average of the neutron cross sections between neutron energies of $E_{1}$ and $E_{k}$ can then be determined and assigned to PKA group $k$. The above process is continued until the PKA energy $T_{h}$ is reached. The calculation then proceeds to the next angle. The integration of the angular variable was replaced by a quadrature sum. For the results given, a modified 96 th order Lobatto angular quadrature ${ }^{1}$ was used. The effect of gamma rays emitted after nonelastic and inelastic collisions on the PKA spectra is small and was not included in the calculations.

For the remaining reactions given above, the PKA spectra were obtained by using a one-neutron emission model ${ }^{2}$ and the secondary-neutron spectra (assumed to be applicable at all angles in the C-M system) given in ENDFB/IV. Therefore,

$$
\sigma\left(g_{n} \rightarrow g_{R}\right)=\frac{\sigma\left(g_{n}\right)}{4 \pi} \sum_{m=1}^{M} w_{m} \sum_{g_{n^{\prime} C-M}} P_{1}\left(g_{n^{\prime} C-M} \rightarrow g_{R}\right) P_{2}\left(\mu_{m}\right)
$$


where

$$
\begin{aligned}
P_{1}\left(g_{n^{\prime} C-M} \rightarrow g_{R}\right)= & \text { the normalized probability for the } C-M \text { emission } \\
& \text { of a neutron with energy in group } g_{n^{\prime} C-M} \text { that can } \\
& \text { be related to a } 1 \text { ab } P K A \text { energy in group } g_{R} \text { by using } \\
& T=n_{1} n_{2} E+\left(n_{1} / n_{2}\right) E^{\prime}-2 n_{1}\left(E E^{\prime}\right)^{\frac{1}{3}} \mu \text { where } E \text { is the } \\
& \text { energy of the incident neutron and } E^{\prime} \text { and } \mu \text { are the } \\
& \text { energy and angle cosine in the } C-M \text { system of the emitted } \\
& \text { neutron, } \\
P_{2}\left(\mu_{m}\right)= & \text { the normalized probability for the } C-M \text { emission of } \\
& \text { a neutron at the angle } \mu_{m}\left(=c o s \theta_{m}\right),\left[P_{2}\left(\mu_{m}\right)=1\right. \\
& \text { for isotropic emission], } \\
\sigma\left(g_{n}\right)= & \text { the cross section for the reaction for incident } \\
& \text { neutrons in group } g_{n} \text { and the remaining variables are } \\
& \text { as described before. }
\end{aligned}
$$

The unnormalized angular distributions considered here are isotropic; $75 \%$ forward $\left(\mu_{m}>0\right), 25 \%$ backward $\left(\mu_{m}<0\right)$; and $(1+\cos \theta)$. Note that no coupling of the distributions has been considered; i.e., it is assumed that $d^{2} \sigma / d \Omega d E=(d \sigma / d E)(d \sigma / d \Omega)$.

For neutron absorption reactions, such as $(n, p)(n, \alpha)$, etc., the methods of Doran, 3 Jenkins, 2 and Parkin and Goland ${ }^{4}$ were used.

For $(n, \gamma)$ reactions, a Monte Carlo program was written. The secondary gamma-ray energies, along with their emission probabilities, were obtained from the nuclear data sheets. In contrast to previous calculations ${ }^{3}$, the incident neutron energy is used in the kinematic equations for total energy and momentum balance with the gamma rays being emitted isotropically in the rest system. Even though the capture-level 
probabilities used in the calculations are for thermal-neutron energies, it was assumed that they apply for all neutron energies. It was also assumed that the gamma rays are emitted fast enough so that no interaction with other nuclei takes place until the residual nucleus is fully deexcited.

The Lindhard et.al., ${ }^{5}$ theory as used by Robinson ${ }^{6}$ is employed to determine that fraction of the energy of the PKA that will produce damage, i.e., further nuclear displacements. The damage energy cross section can be evaluated from the expression

where

$$
\sigma_{i, \text { damage }}(E)=\int_{T_{d}}^{T_{\max }} \frac{d \sigma_{j}(E, T)}{d T} \cdot T_{\text {damage }} d T,
$$

$$
\begin{aligned}
\sigma_{i, \text { damage }}(E)= & \text { the damage energy cross section as a function of } \\
& \text { neutron energy } E \text { for the } i \text { th reaction type, } \\
\frac{d \sigma_{j}(E, T)}{d T}= & \text { the PKA spectrum for the } i \text { th reaction type as a } \\
& \text { function of PKA energy } T \text { and of neutron energy } E, \\
= & \text { that fraction of the energy } T \text { that will produce } \\
& \quad \text { further nuclear displacements, and } \\
T_{\text {damage }}= & \text { the effective threshold energy. }
\end{aligned}
$$

$T_{\text {damage }}$ can be calculated as follows:

$$
T_{\text {damage }}=T[1+k g(\varepsilon)]^{-1} \text {, }
$$




$$
\begin{gathered}
g(\varepsilon)=\varepsilon+0.40244 \varepsilon^{3 / 4}+3.4008 \varepsilon^{1 / 6} \\
k=\frac{0.0793 Z_{1}^{2 / 3} z_{2}^{1 / 2}\left(A_{1}+A_{2}\right)^{3 / 2}}{\left(Z_{1}{ }^{2 / 3}+Z_{2}{ }^{2 / 3}\right)^{3 / 4} A_{1}^{3 / 2} A_{2}^{1 / 2}} \\
\varepsilon=\frac{A T}{27.2 Z_{1} Z_{2}\left(Z_{1}{ }^{2 / 3}+Z_{2}{ }^{2 / 3}\right)^{1 / 2}\left(A_{1}+A_{2}\right)}\left(\mathrm{eV}^{-1}\right)
\end{gathered}
$$

where

$A_{1}, Z_{1}=$ the atomic weight and number of the PKA, respectively, and $A_{2}, Z_{2}=$ like quantities for the matrix atoms.

For alloys

$$
\begin{aligned}
& A_{2}=\sum_{i=1}^{N} n_{i} A_{i} / \sum_{i=1}^{N} n_{i} \\
& z_{2}=\sum_{i=1}^{N} n_{i} z_{i} / \sum_{i=1}^{N} n_{k},
\end{aligned}
$$

where

$$
\begin{aligned}
n_{i}= & \text { the number density of the } i \text { th element, and } \\
A_{i}, z_{i}= & \text { the atomic weight and number of the } i \text { th element in the } \\
& \text { alloy, respectively. }
\end{aligned}
$$

The displacement cross sections are evaluated in a similar way by replacing $T_{\text {damage }}$ with $N_{d}$, defined as 


$$
\begin{array}{ll}
\mathrm{N}_{\mathrm{d}}=0 & \mathrm{~T}<\mathrm{T}_{\mathrm{d}} \\
\mathrm{N}_{\mathrm{d}}=1 & \mathrm{~T}_{\mathrm{d}} \leq \mathrm{T}_{\text {damage }}<2 \mathrm{~T}_{\mathrm{d}} \\
\mathrm{N}_{\mathrm{d}}=\frac{\beta \mathrm{T}_{\text {damage }}}{2 \mathrm{~T}_{\mathrm{d}}} & 2 \mathrm{~T}_{\mathrm{d}} \geq \mathrm{T}_{\text {damage }}, .
\end{array}
$$

where

$$
\beta=0.8 \text {. }
$$

The values used for $T_{d}$ are $A 1,25 \mathrm{eV}$; and $\mathrm{Fe}, 40 \mathrm{eV}$.

\section{RESULTS AND UISCUSSION}

Some of the differential secondary neutron energy spectra for Fe, $(n, 2 n)$, and $\left(n, n^{\prime}\right.$ unresolved reactions), used in the calculations are shown in Fig. 1. The histograms represent ENDFB/IV data. The $(n, 2 n)$ ENDFB/IV data can be closely approximated by an evaporation-type spectrum. In contrast to this, the ( $n, n^{\prime}$ unresolved) ENDFB/IV data cannot.

The sensitivity of the $F e(n, 2 n)$ and $\left(n, n^{\prime}\right.$ unresolved) Lab PKA spectra resulting from incident neutrons in Group 1 to different C-M secondary neutron energy and angular distributions are shown in Figs. 2 and 3, respectively. The symbols $0, x$, and - represent midpoint histogram values. As can be seen, a rather diverse set of distributions can be obtained depending upon the initial conditions.

The sensitivity of the $\mathrm{Fe}(n, 2 n)$ and $\left(n, n^{\prime}\right.$ unresolved) DPA cross sections as a function of incident neutron energy to different secondary neutron angular distributions and energy spectra are given in Tables 3 and 4. Rather large ( 15\%) variations are evident. Considering that rather diverse secondary neutron energy spectra, but the same angular distributions are used to obtain the results in columns 2 and 5 


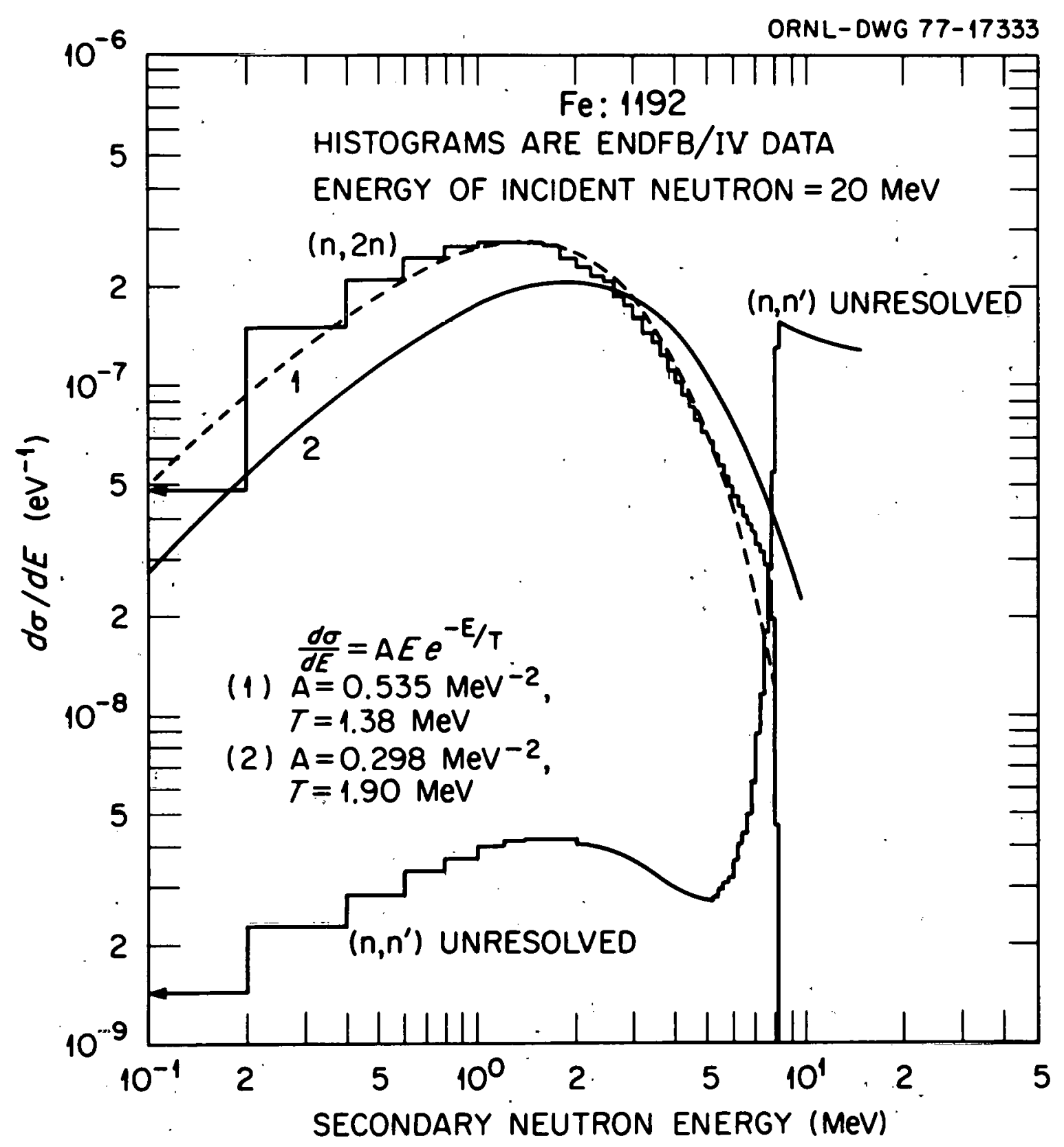

Fig. 1. Differential Secondary Neutron Energy Spectra for Fe. 


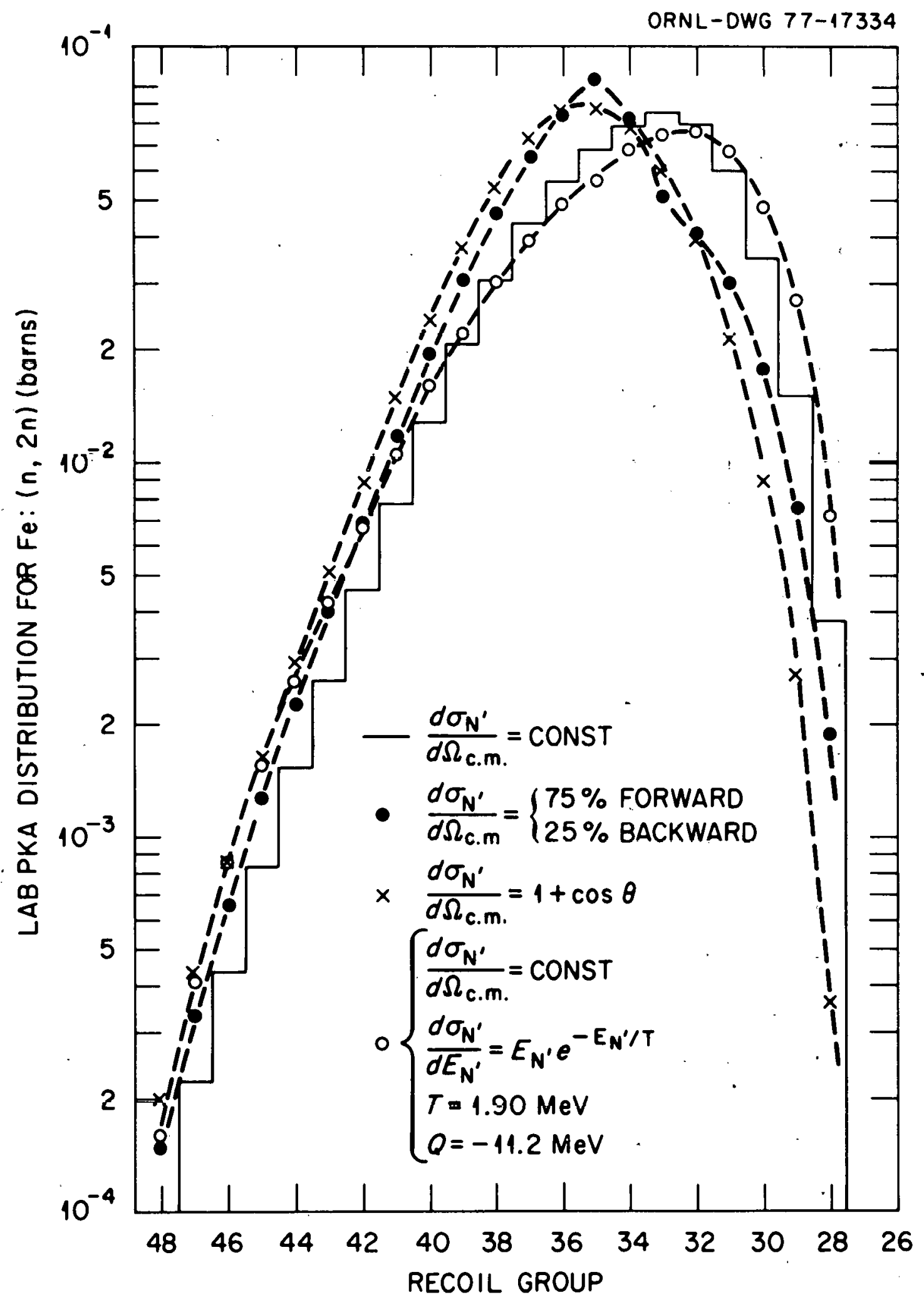

Fig. 2. Sensitivity of the $\mathrm{Fe}(n, 2 n)$ Lab PKA spectrum resulting from incident neutrons in group 1 to different center-of-mass secondary neutron energy and angular distributions. The symbols $0, x$, and . represent the midpoint histogram values. The center-of-mass secondary neutron energy spectrum, unless otherwise specified, has been taken from ENDFB/IV. 


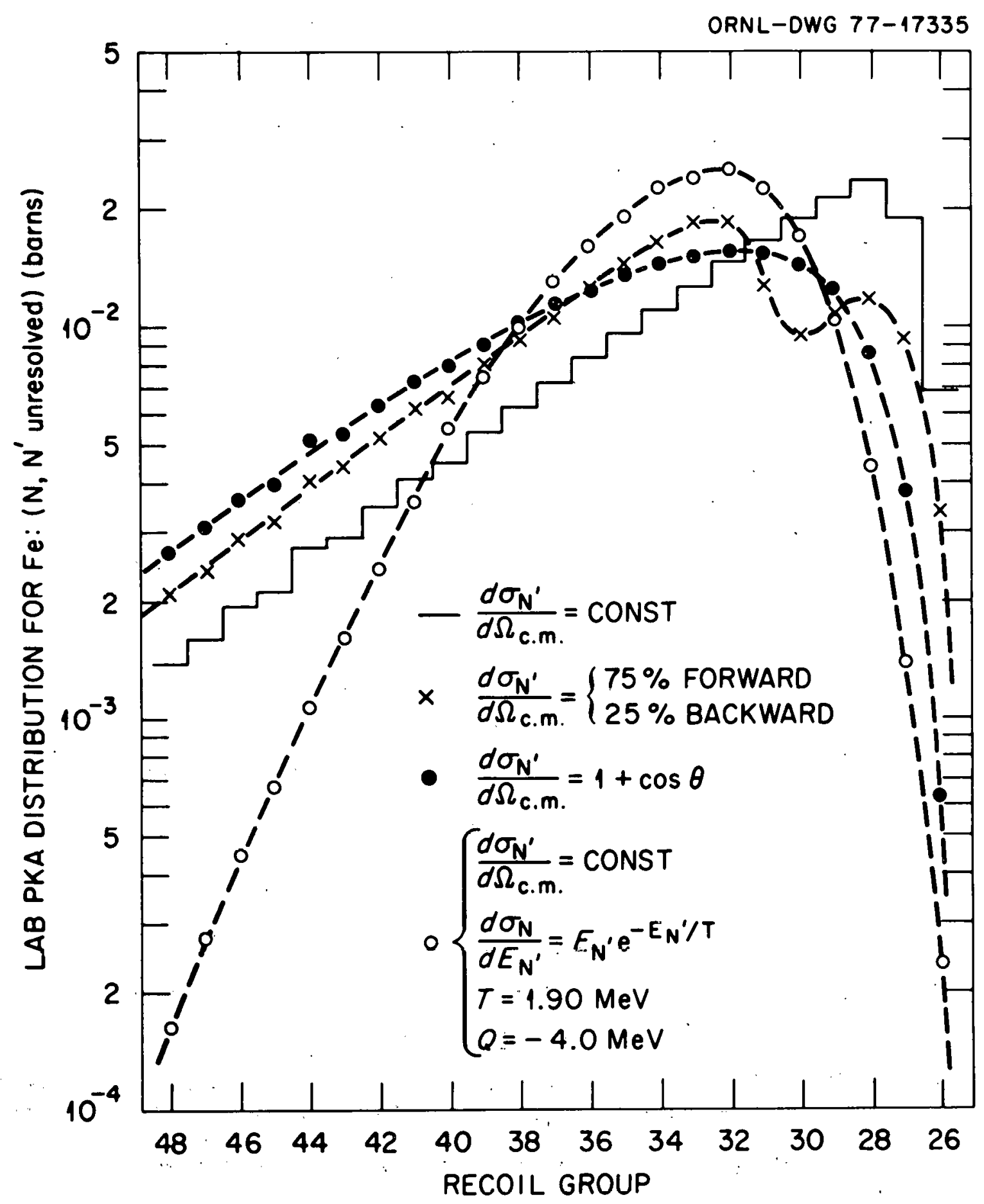

Fig. 3. Sensitivity of the $\mathrm{Fe}\left(n, n^{\prime}\right.$ unresolved) Lab PKA spectrum resulting from incident neutrons in group 1 to different center-of-mass secondary neutron energy and angular distributions. The symbols $0, x$, and - represent the midpoint histogram values. The center-of-mass secondary neutron energy spectrum, unless otherwise specified, has been taken from ENDFB/IV. 
Table III

Sensitivity of the $\mathrm{Fe}(n, 2 n)$ DPA Cross Sections

to Different Secondary Neutron Angular

Distributions and Energy Spectra

\begin{tabular}{|c|c|c|c|c|}
\hline \multirow{3}{*}{$\begin{array}{l}\text { Neutron } \\
\text { Group } \\
\text { Number }\end{array}$} & \multicolumn{4}{|c|}{ DPA Cross Sections (barns) } \\
\hline & $\frac{\mathrm{d} \sigma}{\mathrm{d} \Omega}=1^{b}$ & $\frac{d \sigma}{d \Omega}=2$ & $\frac{d \sigma}{d \Omega}=3$ & $\frac{\mathrm{d} \sigma}{\mathrm{d} \Omega}=1$ \\
\hline & $\frac{d \sigma}{d E}=A$ & $\frac{\mathrm{d} \sigma}{\mathrm{dE}}=\mathrm{A}$ & $\frac{d \sigma}{d E}=A$ & $\frac{d \sigma}{d E}=B$ \\
\hline 1 & 1095 & 968 & 925 & 1118 \\
\hline 2 & 1084 & 959 & 917 & 1108 \\
\hline 3 & 1060 & 938 & 897 & 1,084 \\
\hline 4 & 1011 & 895 & 856 & 1032 \\
\hline 5 & 898 & 798 & 764 & 915 \\
\hline 6 & 631 & 566 & 544 & 642 \\
\hline 7 & 230 & 210 & 204 & 233 \\
\hline 8 & 13.6 & 12.9 & 12.7 & 13.8 \\
\hline
\end{tabular}

${ }^{a}$ Calculated using the one-neutron emission model approximation.

$\mathrm{b}_{1}=$ constant; $2=75 \%$ forward, $25 \%$ backward;

$3=1+\cos \theta$.
$A=E N D F B / I V ; B=E e^{-E / T}$ where $T(e V)=3.22 \times 10^{3} \sqrt{E^{\top} / A}, A$ is the atomic number of the target, $E^{\prime}$ is the incident neutron energy in $\mathrm{eV}$, and $E$ is the energy of the emitted neutron.

All energy and angular distributions are for the center of mass system. 
Table IV

Sensitivity of the Fe( $n, n^{\prime}$ unresolved) DPA Cross Sections to Different Neutron Angular

Distributions and Energy Spectra

\begin{tabular}{|c|c|c|c|c|}
\hline \multirow{3}{*}{$\begin{array}{l}\text { Neutron } \\
\text { Group } \\
\text { Number }\end{array}$} & \multirow{3}{*}{$\begin{array}{l}\frac{\mathrm{d} \sigma}{\mathrm{d} \Omega}=1^{\mathrm{a}} \\
\frac{\mathrm{d} \sigma}{\mathrm{d} E}=A\end{array}$} & \multicolumn{2}{|c|}{ DPA Cross Sections (barns) } & \multirow{3}{*}{$\begin{array}{l}\frac{d \sigma}{d \Omega}=1 \\
\frac{d \sigma}{d E}=B\end{array}$} \\
\hline & & $\frac{\mathrm{d} \sigma}{\mathrm{d} \Omega}=2$ & $\frac{d \sigma}{d \Omega}=3$ & \\
\hline & & $\frac{\mathrm{d} \sigma}{\mathrm{dE}}=\mathrm{A}$ & $\frac{d \sigma}{d E}=A$ & \\
\hline 1 & 460 & 376 & 346 & 394 \\
\hline 2 & 472 & 385 & 356 & 410 \\
\hline 3 & 504 & 412 & 381 & 444 \\
\hline 4 & 565 & 463 & 428 & 506 \\
\hline 5 & 689 & 566 & 524 & 631 \\
\hline 6 & 955 & 791 & 736 & 906 \\
\hline 7 & 1309 & 1099 & 1028 & 1289 \\
\hline 8 & 1485 & 1259 & 1183 & 1492 \\
\hline 9 & 1395 & 1181 & 1109 & 1470 \\
\hline 10 & 1261 & 1066 & 1000 & 1277 \\
\hline 11 & 1112 & 939 & 881 & 1129 \\
\hline 12 & 936 & 792 & 744 & 956 \\
\hline 13 & 730 & 622 & 585 & 751 \\
\hline 14 & 512 & 442 & 419 & 533 \\
\hline 15 & 308 & 271 & 259 & 323 \\
\hline 16 & 144 & 130 & 126 & 152 \\
\hline 17 & 27.5 & 25.4 & 24.8 & 28.3 \\
\hline
\end{tabular}

$a_{1}=$ constant $; 2=75 \%$ forward, $25 \%$ backward; $3=1+\cos \theta$.

$A=E N D F B / I V ; B=E e^{-E / T}$, where $T(e V)=3.22 \times 10^{3} \sqrt{E} T / A$, $A$ is the atomic number of the target,

$E^{\prime}$ is the incident neutron energy in $\mathrm{eV}$, and $E$ is the energy of the emitted neutron.

All energy and angular distributions are for the center of mass system. 
in Table 4 , the results are remarkably similar. The reason for this is due to the nonlinear dependence of the damage energy, that is, as the PKA energy increases the fraction of deposited energy that contributes to damage decreases.

Given in Tables 5-8 are the percent changes in the total and various partial groups averaged damage energy cross sections for A] due to different in-group weighting schemes. The type of weighting has been defined in Sec. II. Overall, except for weighting 3 , there is little effect. The damage energy cross sections given in the tables can, to a good approximation, be converted to DPA cross sections by multiplying by 0.8 and dividing by two times the effective displacement threshold. In Table 9 the changes are investigated by averaging over several types of "typical" neutron environments.

Even though $\mathrm{Al}$ and $\mathrm{Fe}$ have been used to demonstrate the sensitivity of various neutronic parameters, the effects seen here can be expected for other elements. 
Table V

Changes in the Total Group Averaged Damage Energy Cross Sections for A1 Due to Different In-Group Weighting Schemes

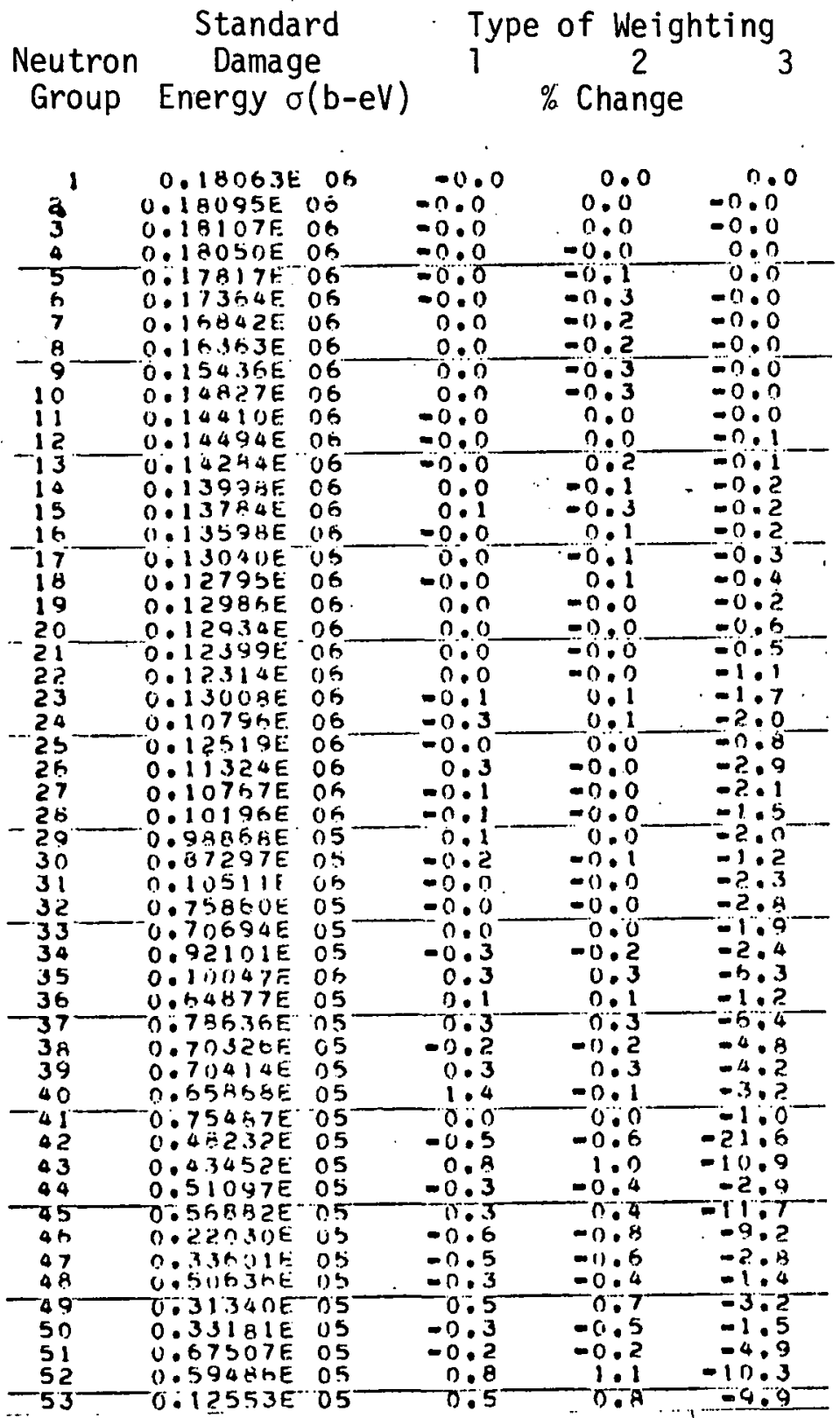

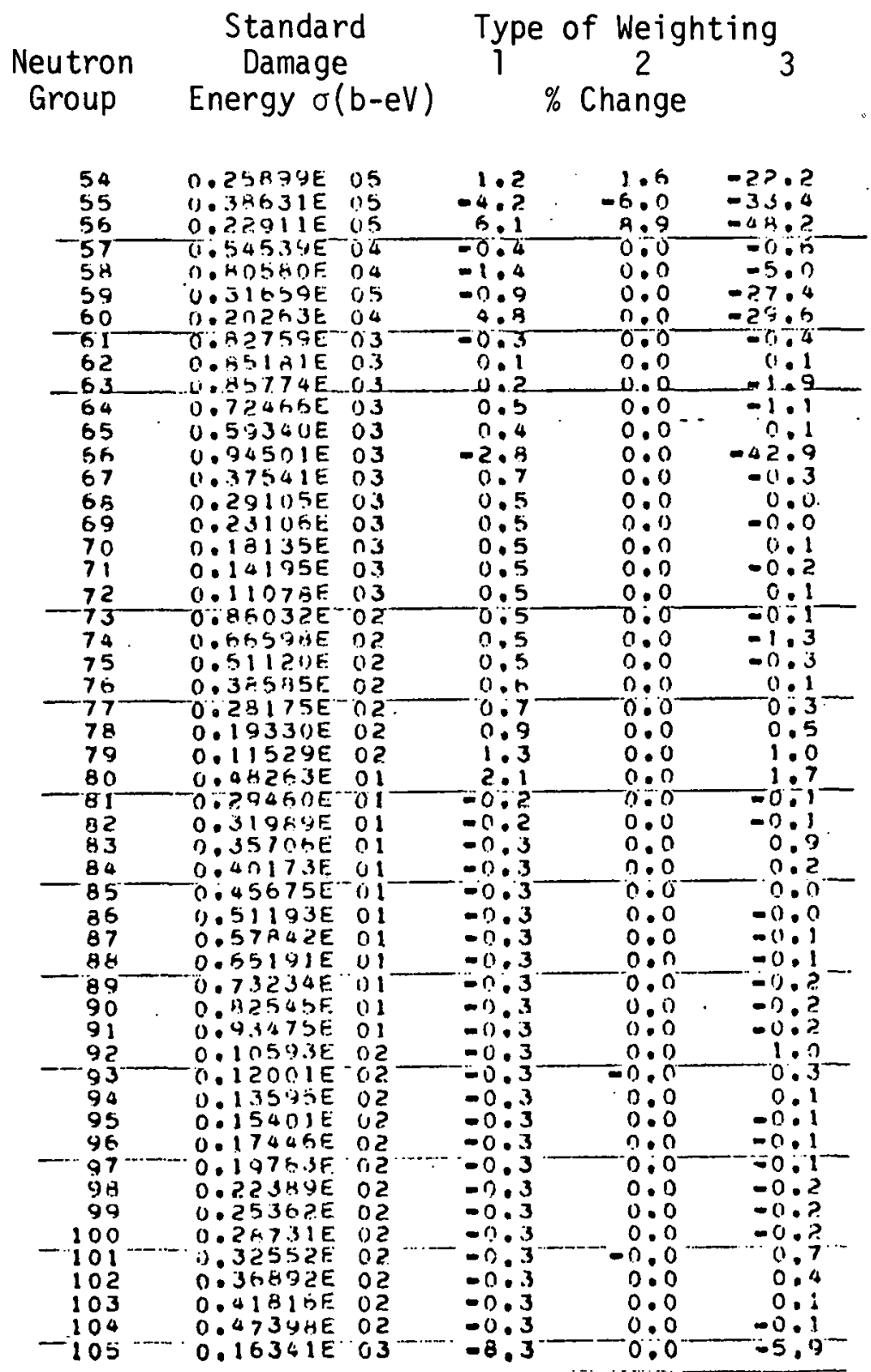


Changes in the Elastic Group Averaged Damage Energy Cross Sections for AI Due to Different In-Group Weighting Schemes

\begin{tabular}{|c|c|c|c|c|c|}
\hline & Standard & Type of Weighting & & Sta & Type of Weighting \\
\hline $\begin{array}{l}\text { Neutron } \\
\text { Group }\end{array}$ & $\begin{array}{c}\text { Damage } \\
\text { Energy } \sigma(b-e V)\end{array}$ & $1 \quad \begin{array}{c}2 \\
\% \text { Change }\end{array}$ & $\begin{array}{l}\text { Neutron } \\
\text { Group }\end{array}$ & $\begin{array}{l}\text { Damage } \\
\text { Energy } \sigma(b-e V)\end{array}$ & $1 \%$ Change \\
\hline
\end{tabular}
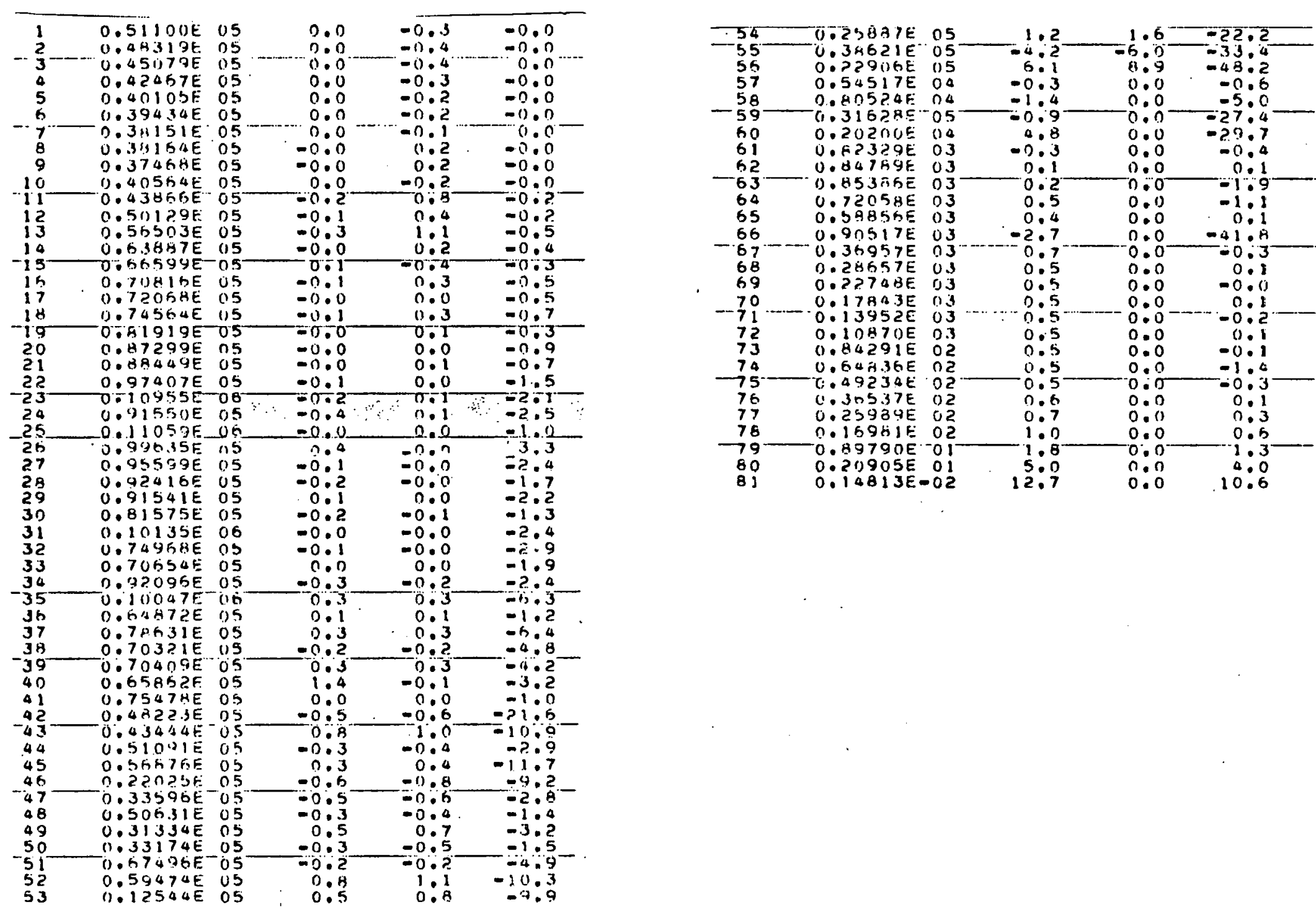
Table VII

Changes in Various Partial Group Averaged Damage Energy Cross Sections for Al Due to Different In-Group Weighting Schemes

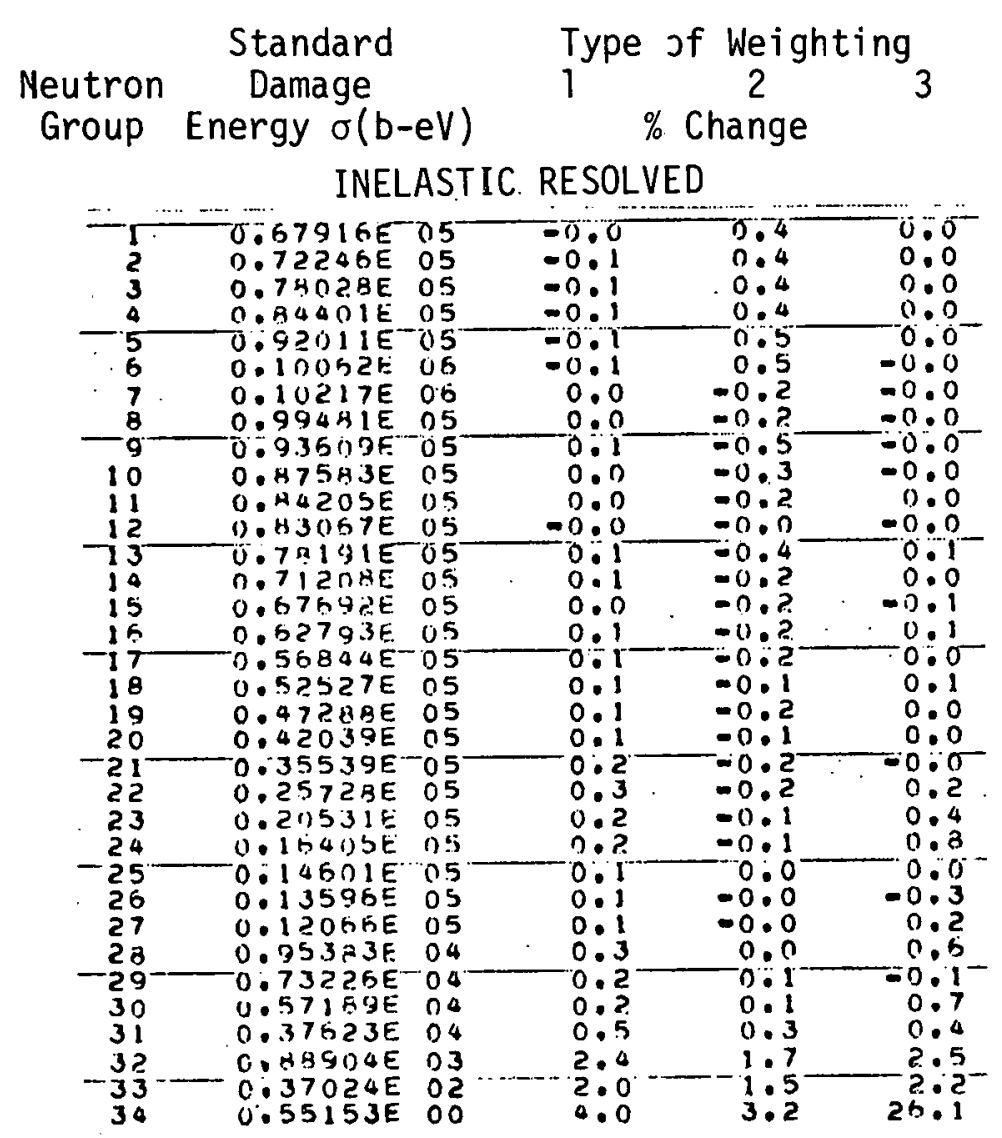

$(n, 2 n)$

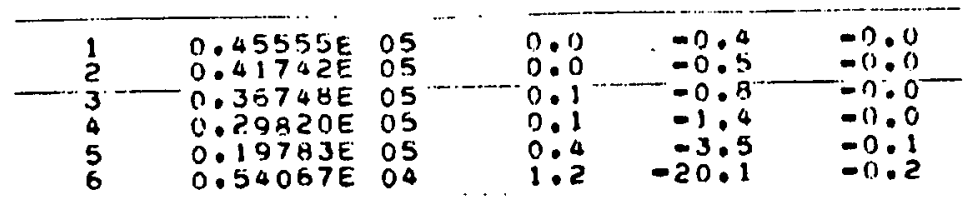

$(n, T)$

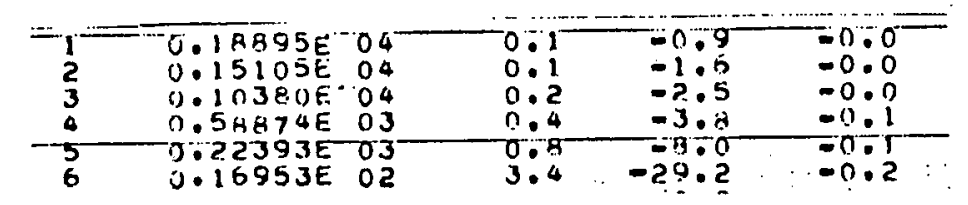

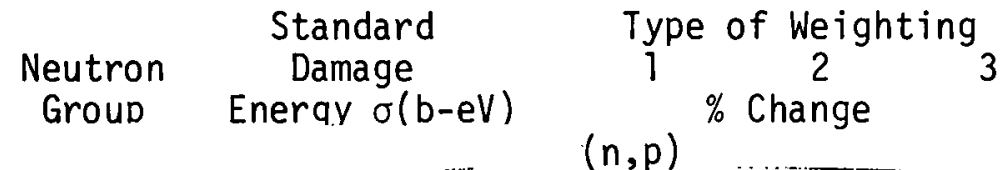

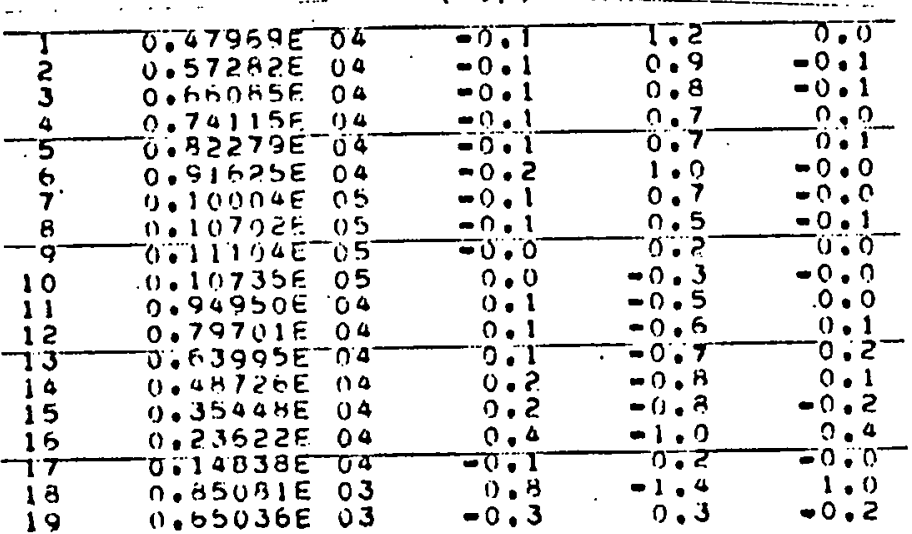

$(n, D)$

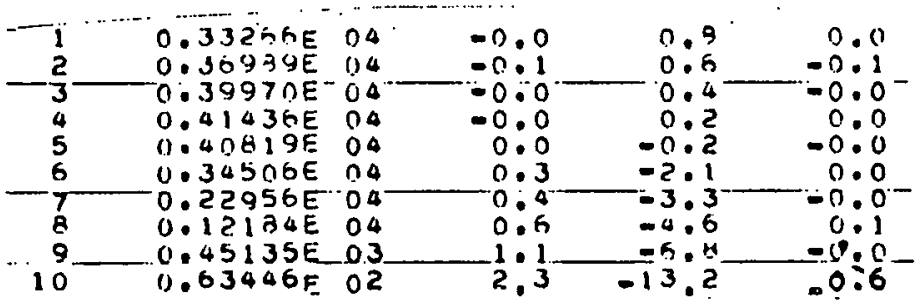

$(n, \alpha)$

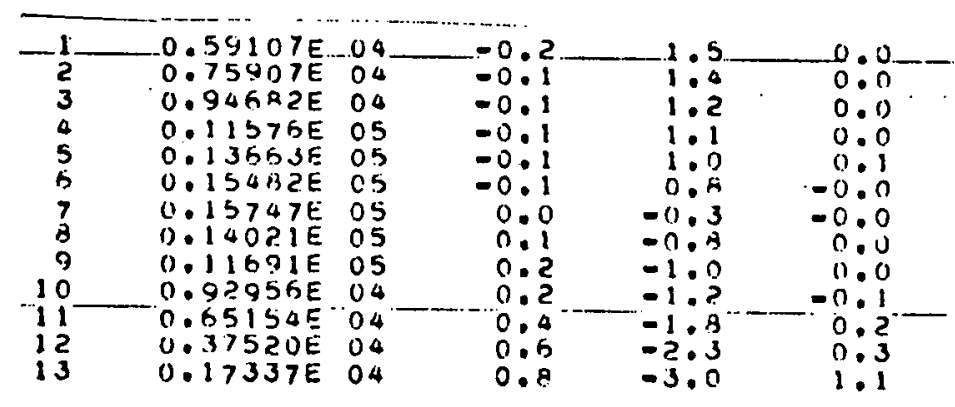


Changes in the $(n, \gamma)$ Group Averaged Damage Energy Cross Sections for AI Due to Different In-Group Weighting Schemes
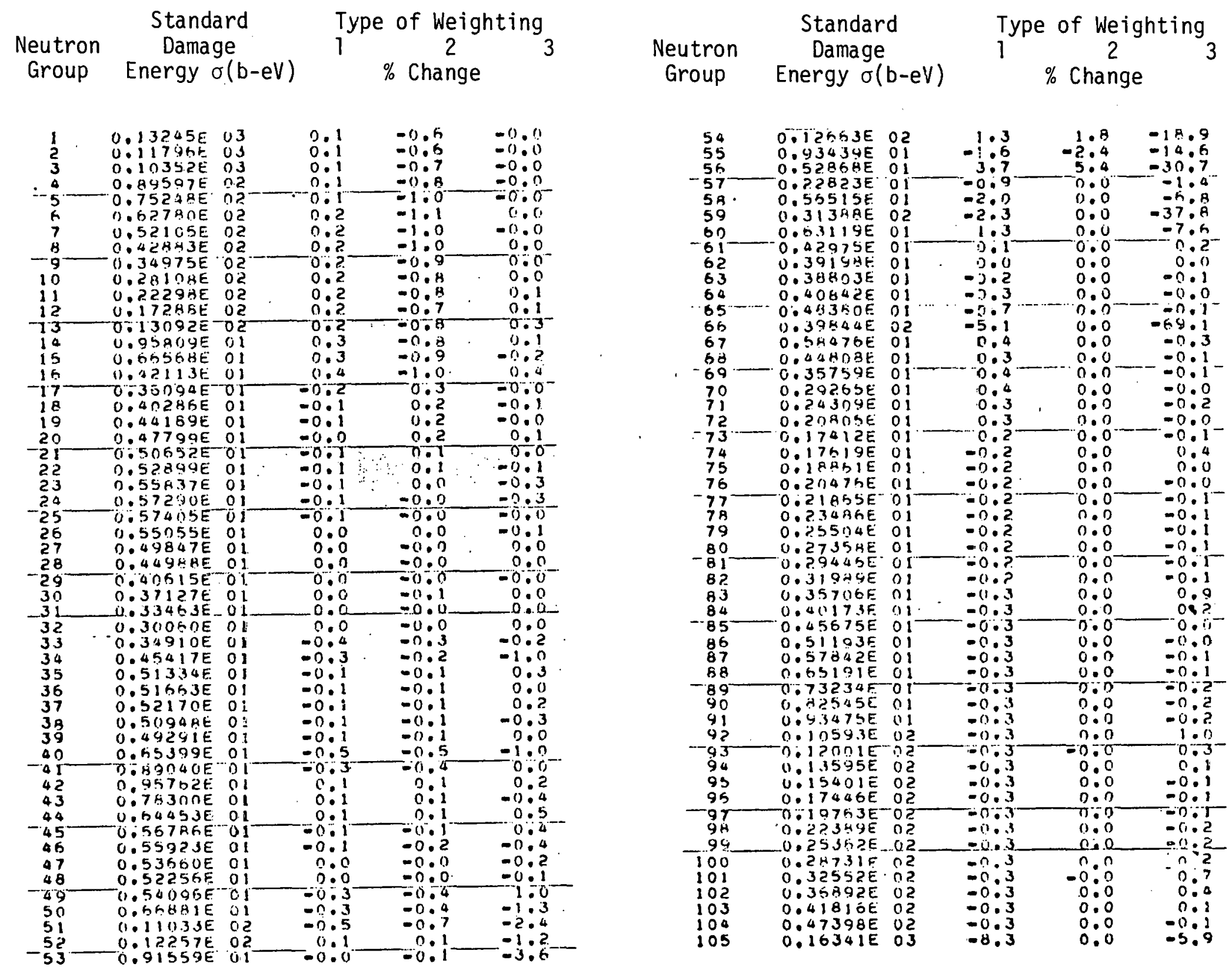
Table IX

Changes in Deposited Damage Energy in Al Due to the Different In-Group Weighting Schemes

\begin{tabular}{lccc}
$\begin{array}{c}\text { Type of Neutron } \\
\text { Environment }\end{array}$ & 1 & \multicolumn{2}{c}{ Type of Weighting } \\
& $\begin{array}{l}\text { \% change relative to deposited } \\
\text { damage energy obtained using } \\
\text { standard cross section set }\end{array}$ \\
\hline First Wal1 CTR & 0.0 & 0.0 & -2.6 \\
HFIR PTP $(z=0)$. & 0.0 & 0.0 & -3.5 \\
HFIR PTP $(z=20 . \mathrm{cm})$ & 0.0 & 0.0 & -3.8 \\
Fast Reactor & 0.0 & 0.0 & -6.5 \\
\hline
\end{tabular}




\section{THIS PAGE}

\section{WAS INTENTIONALLY}

LEFT BLANK 


\section{$\underline{\text { References }}$}

1. N. M. Greene et al., "AMPX: A Modular Code System for Generating Coupled Multigroup Neutron-Gamma Libraries from ENDF/B," ORNL/TM-3706, Oak Ridge National Laboratory (1976).

2. J. D. Jenkins, Nucl. Sci. Eng. 41, 155 (1970).

3. D. G. Doran, Nucl. Scii. Eng. 49, 130 (1972).

4. D. M. Parkin and A. N. Goland, "A Computational Method for the Evaluation of Radiation Effects Produced by CTR-Related Neutron Spectra," Brookhaven National Laboratory Report (1974).

5. J. Lindhard et al., Mat. Fys. Medd. Dan. Vid. Selsk 33, 1 (1963).

6. M. T. Robinson, "Nuclear Fusion Reactors," Proc. British Nuclear Energy Society Conference, Culham Laboratory, Sept. 1969, p. 364. 
THIS PAGE

\section{WAS INTENTIONALLY LEFT BLANK}




\section{Internal Distribution}

ORNL/TM-6108

1-2. L. S. Abbott

3. F. S. Alsmiller

4. R. G. Alsmiller, Jr.

5. J. D. Amburgey

6. H. W. Bertini

7. E. S. Bettis

8-9. B. L. Bishop

10. A. P. Fraas

11. J. F. Clarke

12-23. T. A. Gabriel

24. H. Goldstein (Consul tant)

25. N. M. Greene

26. F. C. Maienschein

27. D. G. McAlees

28. 0. B. Morgan, Jr.

29. F. R. Mynatt

30. E. M. Oblow

31. M. Roberts

32. M. W. Rosenthal

33. R. W. Roussin
34. RSIC

35. R. T. Santoro

36. J. L. Scott

37. D. Steiner

38. M. L. Tobias

39. J. E. Turner

40. J. S. Watson

41. C. R. Weisbin

42. W. F. Wiffen

43. G. E. Whitesides

44. A. Zucker

45. P. F. Fox (Consul tant)

46. W. W. Havens, Jr. (Consultant)

47. A. F. Henry (Consultant)

48. R. E. Uhrig (Consultant)

49-50. Central Research Library

51. ORNL Y-12 Technical Library, Document Reference Section

52-53. Laboratory Records Department

54. ORNL Patent Office

\section{External Distribution}

55-81. Technical Information Center (TIC).

82. Department of Energy, Research and Technical Support Division, P. 0. Box E, Oak Ridge, TN 37830: Director.

83-127. Given NPD-CTR External Distribution. 